\section{Research Square}

Preprints are preliminary reports that have not undergone peer review.

They should not be considered conclusive, used to inform clinical practice, or referenced by the media as validated information.

\title{
Relationship Between Occupational Noise and Hypertension in Modern Enterprise Workers: A Case-Control Study
}

\author{
Xiaomei Wu \\ The First Hospital of China Medical University \\ Yueyan Lan \\ The First Hospital of China Medical University \\ Xiaohong Zhang \\ The Fourth Affiliated Hospital of China Medical University \\ Chaoxiu Li \\ The First Hospital of China Medical University \\ BoZhou ( $\square$ zhoubo@cmu.edu.cn ) \\ The First Hospital of China Medical University
}

\section{Research Article}

Keywords: hypertension, noise, epidemiology, risk factors

Posted Date: December 17th, 2021

DOI: https://doi.org/10.21203/rs.3.rs-1124193/v1

License: (c) (i) This work is licensed under a Creative Commons Attribution 4.0 International License. Read Full License 


\section{Abstract \\ Objective}

Many epidemiological studies have reported an association between occupational noise exposure and hypertension among workers, but have failed to obtain conclusive results. Thus we aimed to assess whether there is a relationship between hypertension and occupational noise.

\section{Methods}

This study adopted a case-control design to verified the relationship of occupational noise and hypertension. This study included 1527 subjects (case group, 509 individuals; control group, 1018 individuals) from a modern automobile manufacturing company. The information includes the general characteristics, occupational factors, and data collected from physical examination, hematology and serology testing. Two-sample t-tests, The Chi-square test, the Ridit analysis method were used for comparing variables. A non-conditional logistic regression model was used for multivariate analysis based on single factor analysis.

\section{Results}

Toxin exposure was found to be a risk factor for the occurrence of hypertension in workers who were exposed to noise in modern enterprises $(\mathrm{OR}=3.45)$. Heart rate was significantly different between the case and control groups $(\mathrm{OR}=5.98)$. Occupational noise exposure is a risk factor for hypertension, and the risk of hypertension for people exposed to noise intensity $\geq 80 \mathrm{~dB}$ is 2.23 times $(95 \% \mathrm{Cl} 1.62-3.06)$ higher than that for people exposed to noise intensity $<80 \mathrm{~dB}$.

\section{Conclusions}

Occupational noise exposure is an independent risk factor for hypertension. it can be used to direct the new criteria of noise exposure limit to protect worker's health.

\section{Introduction}

Essential hypertension poses a serious threat to human health, and it is the main risk factor for cardiovascular disease (CVD). Cardiocerebrovascular disease is the most common cause of death in several developed and developing countries. Chinese national surveys showed that in 2020, the overall prevalence of hypertension among individuals over 18 years of age was $27.5 \%(1)$. The current population of China is 1.4 billion, and according to the 2017 National Workforce Survey, 400 million of these individuals are occupational workers. Moreover, most occupational workers are young adults, and the number of occupational workers appears to be increasing annually(2). Therefore, the blood pressure levels in this group are expected to greatly influence the overall blood pressure levels of the Chinese population. Moreover, health maintenance in this group is also very important for the overall prevention and treatment of chronic diseases in China.

In the interest of worker health, China has issued a series of regulations, standards, and norms aimed at the prevention and treatment of occupational diseases. An increasing number of domestic enterprises have significantly improved working conditions. However, long-term exposure to even low levels of harmful occupational factors can cause chronic effects on workers' health. Among the different chronic diseases, CVD is the leading cause of death in China(3). Hypertension is not only related to an increased risk of CVD but is also the most important risk factor for all-cause morbidity and mortality worldwide(4). Different studies have investigated the prevalence of hypertension among workers. One study showed that the prevalence of hypertension among workers in a large chemical enterprise in Anhui province was $26.5 \%(5)$. Moreover, the hypertension prevalence was reported to be $27.43 \%$ among workers in the steelmaking and rolling workshop of a steel plant(6) and $33.18 \%$ among those working in the factory of a steel enterprise(7). Given that these studies reported elevated rates of hypertension among workers, we speculated that certain risk factors in the respective occupational environments increased the prevalence of hypertension in these populations. Moreover, one study from Nanjing province reported that the prevalence of hypertension among workers who are only exposed to noise was $16.63 \%(8)$, which was also high. Therefore, we hypothesized that there could be a relationship between occupational noise exposure and hypertension. However, previous research on the relationship between noise and hypertension has largely focused on environmental noise, and few studies have examined occupational noise exposure. Moreover, the previous studies examining working populations have failed to obtain conclusive epidemiological results. Some studies have shown that noise exposure is independently associated with hypertension(9). The prevalence of hypertension has been reported to increase with cumulative noise exposure (CNE), reaching $6.00 \%, 7.08 \%, 7.27 \%$ after 0,1 , and 2 years of exposure to noise, respectively(10). A dose-effect relationship between noise and 
hypertension rates has also been reported(11). However, other studies have shown that occupational noise does not increase the risk of hypertension(12), and that the risk of hypertension does not increase at noise exposure levels in the lower half of the $80-90 \mathrm{~dB}(\mathrm{~A})$ range(13).

Despite their exploratory analyses, the previous studies on hypertension and occupational noise have had important limitations. None of the studies included other occupational factors or explained the influence of these factors on the link between noise and hypertension. Therefore, in the present study, we aimed to assess whether noise is an independent risk factor for hypertension. Further, we aimed to identify whether other occupational factors influence the development of hypertension and whether the relationship between noise and hypertension differs under different levels of exposure to these factors.

\section{Materials And Methods}

\section{Participant selection and grouping}

Workers from a modern automobile manufacturing company in Shenyang province who were exposed to occupational noise and participated in occupational health examinations between July and October 2013 were enrolled in the study. The study included on-the-job workers who were exposed to noise in workshops.

Workers who met the diagnostic criteria for hypertension were enrolled into the case group. Workers with normal blood pressure levels were enrolled into an age-matched control cohort using the group matching method (case vs. control ratio $=1: 2$ ). This study included 1527 workers -509 in the case group and 1018 in the control group.

The diagnostic criteria for hypertension were as follows: systolic blood pressure $\geq 140 \mathrm{mmHg}$ and(or) diastolic blood pressure $\geq 90 \mathrm{mmHg}$ or treatment with antihypertensive drugs in the two weeks prior to the study. Individuals with secondary hypertension were excluded. Moreover, individuals with organ-related diseases such as liver and kidney disease, new employees who participated in pre-job physical examinations, and workers who were not exposed to noise were excluded from the study.

\section{Data collection}

This study adopted a case-control design. Information was collected by two trained investigators, entered into an electronic information system, and stored in a dedicated hospital information server. The data collected includes the general characteristics: age, gender, history of illness, medication, smoking and drinking, etc. The occupational factors: types of work and workshops, length of service, exposure to occupational disease hazards, occupation history. The physical examination: blood pressure, heart rate, height, weight, hearing, lung function, electrocardiogram, etc. And collected venous blood for hematology and serology testing. The noise intensity is measured by 2513 type integrating sound level meter, EDGD-ge5 noise dosimeter, HS5936 type vibration tester, UV-A,UV-B noise dosimeter, etc. The dust concentration is measured by DS-21B constant flow dust sampler, AG285 electronic Toxin determination on balance: Toxin concentration is measured by QT2A air sampler, DFC-3BT dust sampler, and TWA300 individual dust sampler. Physical examinations and laboratory tests were performed by professionals, and all instruments and equipment were verified by the Metrology Department of Liaoning province.

\section{Quality control}

The on-site investigators were trained and were proficient in computer use. Physical examinations were performed by doctors who were qualified practicing physicians. The instruments and equipment passed the quality standards of the metrology department.

\section{Statistical analysis}

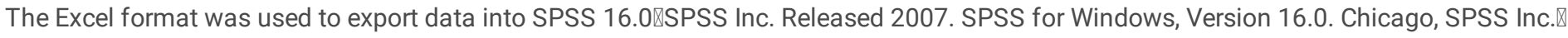
software for correlation analysis. Continuous variables are expressed as the mean \pm standard deviation, and categorical variables are expressed as number of cases and percentages. Two-sample t-tests were used for comparing variables with a normal or almost-normal distribution, and non-parametric tests were used for comparing variables with unknown or unclear distribution patterns. The Chi-square test was used for analyzing categorical variables. Grade data were evaluated using the Ridit analysis method. A non-conditional logistic regression model was used for multivariate analysis based on single factor analysis.

\section{Results}

This study included 1527 subjects (case group, 509 individuals; control group, 1018 individuals). The mean age was similar between the case and control groups (29.23 \pm 5.72 and $29.26 \pm 5.84$ years, respectively; $P>0.05)$. However, heart rate and BMI were significantly higher in the case group than in the control group ( $86 \pm 13$ vs. $79 \pm 11$ beats/min and $27.29 \pm 3.73$ and $23.96 \pm 3.61 \mathrm{~kg} / \mathrm{m}^{2}$, respectively; both $\left.\mathrm{P}<0.05\right)$. 
In the present study, table 1 shhows that the hypertension group and normal blood pressure group had been exposed to significantly different levels of noise intensity $(\mathrm{P}<0.05)$. The risk of hypertension was 2.54 times higher in workers exposed to noise intensity $\geq 80 \mathrm{~dB}$ than in those exposed to noise intensity $<80 \mathrm{~dB}(95 \% \mathrm{Cl} 2.02-3.19)$. The difference in CNE between the two groups was statistically significant (P<0.05). The risk of hypertension in those with $\mathrm{CNE} \geq 80 \mathrm{~dB}$ was 1.56 times higher than that in those with $\mathrm{CNE}<80 \mathrm{~dB}(95 \% \mathrm{Cl} 1.24-1.97)$. However, there was no significant difference in the nature of noise between the two groups $(P>0.05)$.

Table 1 Relationship between noise exposure levels and hypertension.

\begin{tabular}{|c|c|c|c|c|c|c|}
\hline Noise factor & & $\mathrm{N}$ & $\begin{array}{l}\text { Case group } \\
\llbracket n=509 \rrbracket\end{array}$ & $\begin{array}{l}\text { Control group } \\
\llbracket n=1018 \rrbracket\end{array}$ & $P$ & OR(95\%Cl) \\
\hline \multirow[t]{2}{*}{ Noise intensity } & $\geq 80 \mathrm{~dB}$ & 445 & $216(42.4)$ & $229(22.5)$ & \multirow{2}{*}{0.05} & \multirow{2}{*}{$\begin{array}{l}2.54(2.02- \\
3.19)\end{array}$} \\
\hline & $\nabla 80 \mathrm{~dB}$ & 1082 & $293(57.6)$ & $789(77.5)$ & & \\
\hline \multirow{2}{*}{$\begin{array}{l}\text { Cumulative noise exposure } \\
\text { (CNE) }\end{array}$} & $\geq 80 \mathrm{~dB}$ & 957 & $355(71.1)$ & $602(61.2)$ & \multirow{2}{*}{0.05} & \multirow{2}{*}{$\begin{array}{l}1.56(1.24- \\
1.97)\end{array}$} \\
\hline & $\nabla 80 \mathrm{~dB}$ & 526 & $144(28.9)$ & $382(38.8)$ & & \\
\hline \multirow[t]{2}{*}{ Noise nature } & $\begin{array}{l}\text { steady-state } \\
\text { noise }\end{array}$ & 1506 & $503(98.8)$ & 1003(98.5) & \multirow[t]{2}{*}{0.64} & \multirow[t]{2}{*}{$\begin{array}{l}1.25(0.48- \\
3.25)\end{array}$} \\
\hline & impulse noise & 21 & $6(1.2)$ & $15(1.5)$ & & \\
\hline
\end{tabular}

Table 2(At the end of the manuscript)shows the hypertension and normal blood pressure groups showed significant differences in the duration of noise exposure $(P<0.05)$. The risk of hypertension among individuals who had been working in noisy environments for $>1$ year was 1.31 times (95\% Cl 1.05-1.64) higher than that among those who had been working in noisy environments for $\leq 1$ year. The two groups also showed significant differences in toxin exposure $(P<0.05)$, with the risk of hypertension being 2.47 times higher among those with toxin exposure (95\% Cl 1.96-3.12). Similarly, the two groups showed significantly different levels of dust exposure ( $<<0.05)$, and individuals with dust exposure showed a 0.79 -fold $(95 \% \mathrm{Cl} 0.64-0.98)$ difference in the risk of hypertension compared with those with no dust exposure. The two groups also appeared to be involved in different types of work and workshops, and these differences were statistically significant $(P<0.05)$.

Table 2 Relationship between levels of exposure to other occupational factors and hypertension 


\begin{tabular}{|c|c|c|c|c|c|c|}
\hline \multicolumn{2}{|c|}{ Occupational factor } & \multirow{2}{*}{$\begin{array}{l}N \\
963\end{array}$} & \multirow{2}{*}{$\begin{array}{l}\text { Case group } ₫ n=509 \rrbracket \\
342(67.2)\end{array}$} & \multirow{2}{*}{$\begin{array}{l}\text { Control group } ₫ n=1018 \rrbracket \\
621(61.0)\end{array}$} & \multirow{3}{*}{$\begin{array}{l}P \\
₫ 0.05\end{array}$} & \multirow{3}{*}{$\begin{array}{l}\mathrm{OR}(95 \% \mathrm{Cl}) \\
1.31(1.05-1.64)\end{array}$} \\
\hline length of service & ه1year & & & & & \\
\hline & $\leq 1$ year & 564 & 167(32.8) & 397(39.0) & & \\
\hline \multirow[t]{2}{*}{ poison } & Yes & 923 & $377(74.1)$ & $546(53.6)$ & \multirow[t]{2}{*}{$₫ 0.05$} & \multirow[t]{2}{*}{$2.47(1.96-3.12)$} \\
\hline & No & 604 & $132(25.9)$ & $472(46.4)$ & & \\
\hline \multirow[t]{2}{*}{ dust } & Yes & 881 & $274(53.8)$ & $607(59.6)$ & \multirow[t]{2}{*}{$\llbracket 0.05$} & \multirow[t]{2}{*}{$0.79(0.64-0.98)$} \\
\hline & No & 646 & $235(46.2)$ & $411(40.4)$ & & \\
\hline \multirow[t]{14}{*}{ Type of work } & Quality Management & 3 & $2(0.4)$ & $1(0.1)$ & \multirow[t]{14}{*}{$\llbracket 0.05$} & 1 \\
\hline & Logistics & 3 & $0(0)$ & $3(0.3)$ & & 0 \\
\hline & repairs & 64 & $22(4.3)$ & $42(4.1)$ & & $0.26(0.02-3.05)$ \\
\hline & driver & 146 & $45(8.8)$ & 101(9.9) & & $0.22(0.02-2.52)$ \\
\hline & fitter & 26 & $9(1.8)$ & $17(1.7)$ & & $0.26(0.02-3.33)$ \\
\hline & painting & 35 & 19(3.7) & $16(1.6)$ & & $0.59(0.05-7.17)$ \\
\hline & polishing & 17 & $8(1.6)$ & $9(0.9)$ & & $0.44(0.03-5.88)$ \\
\hline & machining & 3 & $1(0.2)$ & $2(0.2)$ & & $0.26(0.01-7.45)$ \\
\hline & welding & 118 & $28(5.5)$ & $90(8.8)$ & & $0.16(0.01-1.78)$ \\
\hline & rework & 18 & $1(0.2)$ & $17(1.7)$ & & $0.03(0-0.68)$ \\
\hline & Section leader & 15 & $3(0.6)$ & $12(1.2)$ & & $0.13(0.01-1.88)$ \\
\hline & Electric welding & 4 & $2(0.4)$ & $2(0.2)$ & & $0.50(0.02-11.09)$ \\
\hline & Electrician & 13 & $2(0.4)$ & $11(1.1)$ & & $0.09(0.01-1.55)$ \\
\hline & Operator & 1062 & $367(72.1)$ & 695(68.3) & & $0.26(0.02-2.92)$ \\
\hline \multirow[t]{4}{*}{ workshop } & final assembly & 1321 & $427(83.9)$ & $894(87.8)$ & \multirow[t]{4}{*}{$\llbracket 0.05$} & $1.20(0.46-3.10)$ \\
\hline & body & 169 & $74(14.5)$ & $95(9.3)$ & & $0.36(0.06-2.07)$ \\
\hline & painting & 16 & $2(0.4)$ & $14(1.4)$ & & $1.95(0.72-5.26)$ \\
\hline & stamping & 21 & $6(1.2)$ & $15(1.5)$ & & 1 \\
\hline
\end{tabular}

In this study, table 3 shows that the prevalence of abnormal lung function was found to differ significantly between the hypertension and normal blood pressure groups $(P<0.05)$. The risk of hypertension in workers with abnormal lung function was 2.14 times $(95 \% \mathrm{Cl} 1.30-3.53)$ higher than that in workers with normal lung function. There was no significant difference in the rate of hearing loss between the two groups $(P>0.05)$.

Table 3 Relationship between occupational injuries and hypertension 


\begin{tabular}{|c|c|c|c|c|c|c|}
\hline \multicolumn{2}{|l|}{ Other disease factors } & \multirow[t]{3}{*}{$\mathrm{N}$} & \multicolumn{2}{|c|}{ Subgroup(number (\%)) } & \multirow[t]{3}{*}{$p$} & \multirow[t]{3}{*}{$\mathrm{OR}(95 \% \mathrm{Cl})$} \\
\hline & & & Case group $₫ n=509 \rrbracket$ & Control & & \\
\hline & & & & group $₫ n=1018 \rrbracket$ & & \\
\hline \multirow[t]{2}{*}{ Abnormal lung function } & Yes & 65 & $33(6.5)$ & $32(3.2)$ & \multirow[t]{2}{*}{$\varangle 0.05$} & \multirow[t]{2}{*}{$2.14(1.30-3.53)$} \\
\hline & No & 1456 & 473(93.5) & $983(96.8)$ & & \\
\hline \multirow[t]{2}{*}{ Hearing loss } & Yes & 84 & $25(4.9)$ & $59(5.8)$ & \multirow[t]{2}{*}{0.48} & \multirow[t]{2}{*}{$0.84(0.52-1.36)$} \\
\hline & No & 1443 & 484(95.1) & $959(94.2)$ & & \\
\hline
\end{tabular}

\section{Stratified analysis based on factors related to hypertension}

To explore whether other factors influence the correlation of noise intensity and CNE with hypertension, factors found to show a statistically significant effect on the occurrence of hypertension were used for stratified analysis. The study population was stratified according to factors such as duration of work, workshop environment, and exposure to dust. However, given that the types of work were too numerous and the sample size of the abnormal lung function group was too small, these factors could not be used for stratified analyses.

Table 4(At the end of the manuscript) shows that regardless of the duration of work in noisy environments and combined exposure to dust and toxins, noise intensity levels were significantly different $(P<0.05)$ between the hypertension and normal blood pressure groups. Noise intensity levels in the two groups were different in different workshops. The two groups showed statistically significant differences $(P<0.05)$ in the proportion of assembly workshop workers.

Table 4 Relationship between noise intensity and hypertension under different levels of exposure to related factors.

\begin{tabular}{|c|c|c|c|c|c|c|c|}
\hline \multicolumn{2}{|c|}{ Stratification factors } & \multirow[t]{2}{*}{ Noise intensity level } & \multirow[t]{2}{*}{$\mathbf{N}$} & \multicolumn{2}{|c|}{ subgroup(number (\%)) } & \multirow[t]{2}{*}{$P$} & \multirow[t]{2}{*}{$\mathrm{OR}(95 \% \mathrm{Cl})$} \\
\hline & & & & $\begin{array}{l}\text { Case group } \\
\bigotimes \mathrm{n}=509 \rrbracket\end{array}$ & $\begin{array}{l}\text { Control group } \\
\bigotimes \mathrm{n}=1018 \rrbracket\end{array}$ & & \\
\hline \multirow[t]{4}{*}{ Length of service } & \multirow[t]{2}{*}{ Q1year } & $\geq 80 \mathrm{~dB}$ & 363 & $177(51.8)$ & $186(30.0)$ & \multirow{2}{*}{$\begin{array}{l}\square \\
0.05\end{array}$} & \multirow{2}{*}{$\begin{array}{l}2.51(1.9- \\
3.30)\end{array}$} \\
\hline & & $₫ 80 \mathrm{~dB}$ & 600 & 165(48.2) & $435(70.0)$ & & \\
\hline & \multirow{2}{*}{$\leq 1$ year } & $\geq 80 \mathrm{~dB}$ & 82 & $39(23.4)$ & $43(10.8)$ & \multirow{2}{*}{$\begin{array}{l}0.05 \\
0.05\end{array}$} & \multirow{2}{*}{$\begin{array}{l}2.51(1.56- \\
4.05)\end{array}$} \\
\hline & & $\nabla 80 \mathrm{~dB}$ & 482 & $128(76.6)$ & $354(89.2)$ & & \\
\hline \multirow[t]{8}{*}{ Workshop } & \multirow[t]{2}{*}{ Final assembly } & $\geq 80 \mathrm{~dB}$ & 337 & $171(40.0)$ & 166(18.6) & \multirow{2}{*}{$\begin{array}{l}0.05 \\
0.05\end{array}$} & \multirow{2}{*}{$\begin{array}{l}2.92(2.26- \\
3.78)\end{array}$} \\
\hline & & $\llbracket 80 \mathrm{~dB}$ & 983 & $256(60.0)$ & 727(81.4) & & \\
\hline & \multirow[t]{2}{*}{ Body } & $\geq 80 \mathrm{~dB}$ & 84 & $40(54.1)$ & $44(46.3)$ & \multirow[t]{2}{*}{0.32} & \multirow{2}{*}{$\begin{array}{l}1.36(0.74- \\
2.51)\end{array}$} \\
\hline & & $\nabla 80 \mathrm{~dB}$ & 85 & $34(45.9)$ & $51(53.7)$ & & \\
\hline & \multirow[t]{2}{*}{ Application } & $\geq 80 \mathrm{~dB}$ & 4 & $0(0)$ & $4(28.6)$ & \multirow[t]{2}{*}{1.00} & \\
\hline & & $\llbracket 80 \mathrm{~dB}$ & 12 & $2(100.0)$ & $10(71.4)$ & & \\
\hline & \multirow[t]{2}{*}{ Stamping } & $\geq 80 \mathrm{~dB}$ & 20 & $5(83.3)$ & $15(100.0)$ & \multirow[t]{2}{*}{0.29} & \\
\hline & & $\nabla 80 \mathrm{~dB}$ & 1 & 1(16.7) & $0(0)$ & & \\
\hline \multirow[t]{4}{*}{ Dust } & \multirow[t]{2}{*}{ Yes } & $\geq 80 \mathrm{~dB}$ & 216 & $90(32.8)$ & $126(20.8)$ & \multirow{2}{*}{$\begin{array}{l}\square \\
0.05\end{array}$} & \multirow{2}{*}{$\begin{array}{l}1.87(1.36- \\
2.57)\end{array}$} \\
\hline & & $\llbracket 80 \mathrm{~dB}$ & 665 & $184(67.2)$ & $481(79.2)$ & & \\
\hline & \multirow[t]{2}{*}{ No } & $\geq 80 \mathrm{~dB}$ & 229 & 126(53.6) & $103(25.1)$ & \multirow{2}{*}{$\begin{array}{l}0.05 \\
0.05\end{array}$} & \multirow{2}{*}{$\begin{array}{l}3.46(2.46- \\
4.86)\end{array}$} \\
\hline & & $\triangle 80 \mathrm{~dB}$ & 417 & $109(46.4)$ & $308(74.9)$ & & \\
\hline \multirow[t]{4}{*}{ Poison } & \multirow[t]{2}{*}{ Yes } & $\geq 80 \mathrm{~dB}$ & 295 & $166(44.0)$ & $129(23.6)$ & \multirow{2}{*}{$\begin{array}{l}\square \\
0.05\end{array}$} & $2.54(1.92-$ \\
\hline & & $\otimes 80 \mathrm{~dB}$ & 628 & $211(56.0)$ & $417(76.4)$ & & \\
\hline & No & $\geq 80 \mathrm{~dB}$ & 150 & $50(37.9)$ & $100(21.2)$ & 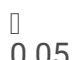 & $\begin{array}{l}2.27(1.50- \\
3.44)\end{array}$ \\
\hline & & $\nabla 80 \mathrm{~dB}$ & 454 & $82(62.1)$ & $372(78.8)$ & & \\
\hline
\end{tabular}


Table 5(At the end of the manuscript) shows that when the duration of noise exposure was $\leq 1$ year, the CNE was significantly different between the two groups $(\mathrm{P}<0.05)$. When the two groups were compared, CNE levels were found to be significantly different between final assembly workshop workers $(P<0.05)$, workers who were not exposed to dust $(P<0.05)$, and workers exposed to toxins $(P<0.05)$.

Table 5 Relationship between CNE levels and hypertension under different levels of exposure to related factors.

\begin{tabular}{|c|c|c|c|c|c|c|c|}
\hline \multicolumn{2}{|c|}{ Stratification factor } & \multirow[t]{2}{*}{ Cumulative noise intensity level } & \multirow[t]{2}{*}{$\mathbf{N}$} & \multicolumn{2}{|c|}{ subgroup(number (\%)) } & \multirow[t]{2}{*}{$P$} & \multirow[t]{2}{*}{$\mathrm{OR}(95 \% \mathrm{Cl})$} \\
\hline & & & & $\begin{array}{l}\text { Case group } \\
\bigotimes n=509 \rrbracket\end{array}$ & Control group $₫ n=1018 \rrbracket$ & & \\
\hline \multirow[t]{4}{*}{ Length of service } & \multirow[t]{2}{*}{$\otimes 1$} & $\geq 80 \mathrm{~dB}$ & 881 & 318(93.0) & $563(90.7)$ & 0.22 & $\begin{array}{l}1.36(0.83- \\
2.24)\end{array}$ \\
\hline & & $\nabla 80 d B$ & 82 & $24(7.0)$ & $58(9.3)$ & & \\
\hline & \multirow[t]{2}{*}{$\leq 1$} & $\geq 80 \mathrm{~dB}$ & 76 & $37(23.6)$ & 39(10.7) & 0.05 & $\begin{array}{l}2.56(1.56- \\
4.21)\end{array}$ \\
\hline & & $\otimes 80 \mathrm{~dB}$ & 444 & $120(76.4)$ & $324(89.3)$ & & \\
\hline \multirow[t]{8}{*}{ Workshop } & \multirow[t]{2}{*}{$\begin{array}{l}\text { Final } \\
\text { assembly }\end{array}$} & $\geq 80 \mathrm{~dB}$ & 799 & 295(70.1) & $504(58.3)$ & 0.05 & $\begin{array}{l}1.68(1.31- \\
2.15)\end{array}$ \\
\hline & & $₫ 80 \mathrm{~dB}$ & 487 & $126(29.9)$ & $361(41.7)$ & & \\
\hline & \multirow[t]{2}{*}{ Body } & $\geq 80 \mathrm{~dB}$ & 126 & $54(77.1)$ & 72(79.1) & 0.76 & $\begin{array}{l}0.89(0.42- \\
1.89)\end{array}$ \\
\hline & & $\triangle 80 \mathrm{~dB}$ & 35 & 16(22.9) & 19(20.9) & & \\
\hline & \multirow[t]{2}{*}{ Application } & $\geq 80 \mathrm{~dB}$ & 13 & $1(50.0)$ & 12(85.7) & 0.35 & $\begin{array}{l}0.17(0.01- \\
3.89)\end{array}$ \\
\hline & & $\triangle 80 \mathrm{~dB}$ & 3 & $1(50.0)$ & $2(14.3)$ & & \\
\hline & \multirow[t]{2}{*}{ Stamping } & $\geq 80 \mathrm{~dB}$ & 18 & $5(83.3)$ & $13(100.0)$ & 0.32 & \\
\hline & & $\triangle 80 d B$ & 1 & 1(16.7) & $0(0)$ & & \\
\hline \multirow[t]{4}{*}{ Dust } & \multirow[t]{2}{*}{ Yes } & $\geq 80 \mathrm{~dB}$ & 533 & $170(64.2)$ & $363(61.8)$ & 0.52 & $\begin{array}{l}1.10(0.82- \\
1.49)\end{array}$ \\
\hline & & $\llbracket 80 \mathrm{~dB}$ & 319 & $95(35.8)$ & $224(38.2)$ & & \\
\hline & \multirow[t]{2}{*}{ No } & $\geq 80 \mathrm{~dB}$ & 424 & $185(79.1)$ & $239(60.2)$ & 0.05 & $\begin{array}{l}2.50(1.72- \\
3.63)\end{array}$ \\
\hline & & $\triangle 80 \mathrm{~dB}$ & 207 & $49(20.9)$ & 158(39.8) & & \\
\hline \multirow[t]{4}{*}{ poisons } & \multirow[t]{2}{*}{ Yes } & $\geq 80 \mathrm{~dB}$ & 566 & 262(70.6) & $304(56.5)$ & 0.05 & $\begin{array}{l}1.85(1.40- \\
2.45)\end{array}$ \\
\hline & & $\nabla 80 \mathrm{~dB}$ & 343 & $109(29.4)$ & $234(43.5)$ & & \\
\hline & \multirow[t]{2}{*}{ No } & $\geq 80 \mathrm{~dB}$ & 391 & $93(72.7)$ & 298(66.8) & 0.21 & $\begin{array}{l}1.32(0.85- \\
2.04)\end{array}$ \\
\hline & & $\nabla 80 \mathrm{~dB}$ & 183 & $35(27.3)$ & 148(33.2) & & \\
\hline
\end{tabular}

In order to explore the factors influencing hypertension development among workers in modern enterprises, we conducted multivariate unconditional logistic regression analysis. The dependent variable was the presence of hypertension after noise exposure. The independent variables included noise intensity, CNE, nature of noise, duration of work in noisy environments, work in production workshops, dust exposure, toxin exposure, family history, lung function, body mass index(BMI), and heart rate. Table 6 shows that noise intensity, BMI $>23.9 \mathrm{~kg} / \mathrm{m}^{2}$, heart rate $>100$ beats/min, toxin exposure, and abnormal lung function were found to influence the development of hypertension in workers exposed to noise in modern enterprises.

Table 6 Adjusted risk of hypertension based on noise and other occupational factors 


\begin{tabular}{|c|c|c|c|c|c|}
\hline source & B & S.E. & Wald & AdjustedOR & OR95\% Cl \\
\hline Noise intensity & 0.80 & 0.16 & 24.41 & 2.23 & $\nabla 1.62-3.06 \rrbracket$ \\
\hline body mass index $(\mathrm{BMI}) \otimes 23.9 \mathrm{~kg} / \mathrm{m}^{2}$ & 2.39 & 0.56 & 18.50 & 10.90 & $\varangle 3.67-32.39 \rrbracket$ \\
\hline Toxin exposure & 1.24 & 0.16 & 61.26 & 3.45 & $\otimes 2.53-4.71 \rrbracket$ \\
\hline Body workshop & 0.91 & 0.22 & 17.73 & 2.49 & ه1.63-3.79ه \\
\hline Lung function & 1.05 & 0.30 & 11.93 & 2.86 & $\otimes 1.58-5.19 \rrbracket$ \\
\hline Heart rate $₫ 100$ beats/min & 1.79 & 0.27 & 44.61 & 5.98 & $\varangle 3.54-10.11 \rrbracket$ \\
\hline
\end{tabular}

\section{Discussion}

Our study showed that occupational noise exposure is a risk factor for hypertension, and the risk of hypertension for people exposed to noise intensity $\geq 80 \mathrm{~dB}$ is 2.23 times $(95 \% \mathrm{Cl} 1.62-3.06)$ higher than that for people exposed to noise intensity $<80 \mathrm{~dB}(\mathrm{P}<0.05)$. Ta-Yuan Chang's survey of 578 men in Taiwan showed that prolonged exposure to noise levels $\geq 85 \mathrm{~dB}$ may increase systolic and diastolic blood pressure levels(14). LI X's case-control study on the relationship between noise in an automobile factory and hypertension rates showed that workers in the high-exposure group had a significantly higher risk of hypertension than those exposed to lower noise levels(15). This is consistent with our findings, which show that occupational noise exposure is a risk factor for hypertension.

Toxin exposure was found to be a risk factor for the occurrence of hypertension in workers who were exposed to noise in modern enterprises $(\mathrm{OR}=3.45)$. The common chemical toxins in the automobile manufacturing industry include benzene, toluene, xylene, and lead. Evidence has shown the causal relationship between lead exposure and hypertension(16), although the relationship of benzene and its isomers with hypertension is currently unclear. Through previous work experience and on-site sampling, we know that nitrogen oxides, carbon oxides, ozone, and other toxins are produced during electric welding. Cai Y's meta-analysis showed that short-term exposure to $\mathrm{NO}_{2}, \mathrm{O}_{3}$, and $\mathrm{CO}_{\text {as }}$ well as long-term exposure to $\mathrm{NO}_{x}$ and $\mathrm{SO}$ were positively correlated with hypertension, and that these toxins may increase the risk of hypertension(17). Hence, we considered that the incidence of hypertension in workers may be caused by the combination of these toxins. However, the types and concentrations of toxins differ across workplaces, as do the levels of vibration, dust, and other harmful factors. Hence, it is unclear which toxin has the most significant contribution to hypertension development, and the relationship between toxins and hypertension needs to be confirmed in future studies.

So far, several studies have confirmed the relationship between dust and hypertension. For example, research by Hongchen showed that $\mathrm{PM}_{2.5}$ is related to hypertension(18), and another study found that long-term exposure to $\mathrm{PM}_{10}$ is also associated with hypertension(19). After adjusting for dust exposure in our stratified analysis, we found a greater correlation between noise intensity and hypertension, indicating that dust exposure may conceal the correlation between noise and hypertension $(O R=1.87, \mathrm{OR}$ adjusted=3.46). These findings differ from those obtained in Fuks KB's study, which revealed that the positive correlation between road traffic noise and self-reported hypertension weakened after adjusting for $\mathrm{PM}_{2.5}$ levels(20). This difference may have occurred because our study focuses on noise and dust in an occupational environment, and the intensity (concentration) and duration of noise exposure in these environments are very different from those in everyday life. However, given these differences, further research may be required to verify the interaction of noise and dust exposure in the context of hypertension. Moreover, most workers who were not exposed to dust worked in workshops where they were exposed to toxins, and exposure to toxins was positively related to the occurrence of hypertension. This effect may influence the relationship between dust and hypertension.

In our study, heart rate and BMI were significantly different between the case and control groups $(P<0.05)$. A strong correlation was observed between sinus tachycardia and hypertension ( $\mathrm{OR}=5.98)$, consistent with earlier studies showing that an increased heart rate is related to hypertension $(21,22)$. A study has also shown that tachycardia is a precursor to hypertension and a cardiovascular risk factor among patients with hypertension(23). Obesity (BMI $>23.9 \mathrm{~kg} / \mathrm{m}^{2}$ ) is a well-known risk factor for hypertension, and as early as 2013, a position paper was initiated to describe the pathogenesis and epidemiology of obesity-induced hypertension(24). Occupational injury is also a risk factor for the development of hypertension. Our study showed that people with abnormal lung function were 2.84 times more likely to develop hypertension than those with normal lung function. This suggests that the development of hypertension may also be related to other occupational diseases. Further, we found that the prevalence of hypertension varied among workers in different workshops, which may be due to different types and concentrations of dust, toxins, and other occupational factors or differences in noise intensity, frequency, etc. The differences in the nature of work in different workshops could also lead to large individual differences between the workers such as physical fitness. This indicates that in the occupational population, the relationship between noise and hypertension is affected by multiple factors. 
Hypertension results from a combination of environmental factors, genetic factors, as well as other factors, including occupational environment-related factors such as noise intensity and toxin exposure and occupational conditions such as abnormal lung function. Our study was conducted in a company with some of the best working environments and environmental protection standards at the domestic level, and the company also had advanced production technology and management. Exposure to harmful chemicals and poor physical conditions in the production environment had been minimized in this setting. However, the life and health of workers was still being affected. Therefore, the impact of even low exposure to occupational risk factors cannot be ignored.

The advantages of this study include its sufficient number of subjects, analysis of the relationship between noise and hypertension under exposure to different occupational factors, control of confounding variables such as other occupational factors, and a more precise study of the impact of occupational noise exposure. However, this study has several limitations. There are almost all men in the factory, so the subjects included in the study are all men. There may be gender differences in the relationship between occupational noise and high blood pressure, so the results of the study are limited to men. Since there is no individual assessment of noise exposure, the assessment may be incorrect if workers frequently change their workplaces. A more precise measurement of noise exposure may increase the accuracy of analysis, but it is difficult to implement due to the large sample size.

\section{Conclusion}

There is a significant positive correlation between occupational factors and hypertension. Duration of occupational noise exposure, dust exposure, toxin exposure, type of workshop, abnormal lung function, and BMI $>23.9 \mathrm{~kg} / \mathrm{m}^{2}$ are risk factors for the occurrence of hypertension. Moreover, heart rate is associated with hypertension. The correlation of noise intensity and CNE with the occurrence of hypertension varies under different levels of exposure to different factors. However, occupational noise exposure is an independent risk factor for hypertension. In modern enterprises, multiple aspects should be considered to prevent hypertension and other chronic diseases and achieve better health outcomes.

\section{Abbreviations}

\begin{tabular}{|ll|}
\hline CVD & cardiovascular disease \\
CNE & cumulative noise exposure \\
BMI & body mass index \\
\hline
\end{tabular}

\section{Declarations}

\section{Ethics approval and consent to participate}

This study has been approved by the medical scientific research ethics committee of the First Affiliated Hospital of China Medical University (No. AF-SOP-07-1.0-01). All procedures performed in the study comply with the ethical standards of the institution and/or the National Research Committee and the 1964 Helsinki Declaration and its subsequent amendments or similar ethical standards.

The patients or the public were not actually involved in the design and analysis of our research. The data of demographic indicators and clinical examination is from the management system of medical examination center. There are no privacy issues involved in the collection of information. Thus the informed consent is not applicable.

\section{Consent for publication}

Not applicable

\section{Availability of data and materials}

The datasets generated during and/or analyzed during the current study are available from the corresponding author on reasonable request

\section{Competing interests}

The authors declare that the research was conducted in the absence of any commercial or financial relationships that could be construed as a potential conflict of interest.

\section{Funding}


Not applicable.

\section{Authors' contributions}

$\mathrm{XMW}, \mathrm{YYL}$, and BZ contributed to conception and design of the study. $\mathrm{XHZ}$, and $\mathrm{CXL}$ organized the database. BZ, and $\mathrm{XMW}$ performed the statistical analysis. YYL wrote the first draft of the manuscript. XMW, YYL, XHZ and CXL wrote sections of the manuscript. All authors contributed to manuscript revision, read, and approved the submitted version.

\section{Acknowledgements}

Not applicable.

\section{References}

1. "Report on Nutrition and Chronic Disease Status of Chinese Residents (2020)" Press Conference. Available from: http://www.scio.gov.cn/xwfbh/xwbfbh/wqfbh/42311/44583/index.htm. Accessed 23 october 2021.

2. The style of Daxing investigation and research promotes the work of the masses of employees in the new era-the leader of the eighth national investigation of the status of the workforce answers reporters' questions. chinese workers. 2018;02:6-9. (in chinese).

3. Liu S, Li Y, Zeng X, Wang H, Yin P, Wang L, et al. Burden of Cardiovascular Diseases in China, 1990-2016: Findings From the 2016 Global Burden of Disease Study. JAMA Cardiol. 2019;4(4):342-52.

4. Oparil S, Acelajado MC, Bakris GL, Berlowitz DR, Cifkova R, Dominiczak AF, et al. Hypertension. Nat Rev Dis Primers. 2018;4:18014.

5. Zi-han X, Dong-mei D, Jiao-jiao G, Jun D, Qian-nan W, Wei-zhuo Y, et al. The interactive effects of occupational noise exposure and high temperature on cardiovascular sys- tem. Chin J Dis Control Prev. 2020;24(07):773-8. (in chinese).

6. Yanhong L, Guoshun C, Shanfa Y. Prevalence and influence factors of hypertension among the workers exposed to noise in steel making and steel rolling workshop of an iron and steel plant. Chinese Journal of Preventive Medicine. 2015;49(05):405-10. (in chinese).

7. wen LX, bin WY, ling LQ, Na S, qiang ZR-, hui LX. Association of occupational heat and noise exposure with hypertension. Prev Med. 2019;31(12):1189-92+99. (in chinese).

8. ting LX, liang ZL, Qiu D, Lei T, you-hong B, hai-yan S. Occupational noise induced hearing loss and other health issues in Nanjing. Chinese Preventive Medicine. 2019;20(04):285-9. (in chinese).

9. de Souza TC, Périssé AR, Moura M. Noise exposure and hypertension: investigation of a silent relationship. BMC public health. 2015;15:328.

10. Ke-hong T, Xiang D, De-cai Y, Juan Z, Li-hong Y, Yue-pu P. Impacts on Hearing and Cardiovascular System in New and Young Workers Exposed to Occupational Noise. J Environ Occup Med. 2015;32(06):544-8. (in chinese).

11. Xiang-wen L, Jun-wang T, Jing-bo Y, Feng C, Yong-bin W, Ju-xiang Y. Relationship between cumulative noise exposure and hypertension among iron and steel production workers. Chin Occup Med. 2016;43(04):451-5. (in chinese).

12. Tessier-Sherman B, Galusha D, Cantley LF, Cullen MR, Rabinowitz PM, Neitzel RL. Occupational noise exposure and risk of hypertension in an industrial workforce. Am J Ind Med. 2017;60(12):1031-8.

13. Stokholm ZA, Bonde JP, Christensen KL, Hansen AM, Kolstad HA. Occupational noise exposure and the risk of hypertension. Epidemiology. 2013;24(1):135-42.

14. Chang TY, Hwang BF, Liu CS, Chen RY, Wang VS, Bao BY, et al. Occupational noise exposure and incident hypertension in men: a prospective cohort study. Am J Epidemiol. 2013;177(8):818-25.

15. Li X, Dong Q, Wang B, Song H, Wang S, Zhu B. The Influence of Occupational Noise Exposure on Cardiovascular and Hearing Conditions among Industrial Workers. Sci Rep. 2019;9(1):11524.

16. Navas-Acien A, Guallar E, Silbergeld EK, Rothenberg SJ. Lead exposure and cardiovascular disease--a systematic review. Environ Health Perspect. 2007;115(3):472-82.

17. Cai Y, Zhang B, Ke W, Feng B, Lin H, Xiao J, et al. Associations of Short-Term and Long-Term Exposure to Ambient Air Pollutants With Hypertension: A Systematic Review and Meta-Analysis. Hypertension. 2016;68(1):62-70.

18. Chen H, Burnett RT, Kwong JC, Villeneuve PJ, Goldberg MS, Brook RD, et al. Spatial association between ambient fine particulate matter and incident hypertension. Circulation. 2014;129(5):562-9.

19. Dong GH, Qian ZM, Xaverius PK, Trevathan E, Maalouf S, Parker J, et al. Association between long-term air pollution and increased blood pressure and hypertension in China. Hypertension. 2013;61(3):578-84. 
20. Fuks KB, Weinmayr G, Basagana X, Gruzieva O, Hampel R, Oftedal B, et al. Long-term exposure to ambient air pollution and traffic noise and incident hypertension in seven cohorts of the European study of cohorts for air pollution effects (ESCAPE). Eur Heart J. 2017;38(13):983-90.

21. Liu L, Mizushima S, Ikeda K, Nara Y, Yamori Y, Cardiovascular D, et al. Resting heart rate in relation to blood pressure: results from the World Health Organization-Cardiovascular Disease and Alimentary Comparison study. Int J Cardiol. 2010;145(1):73-4.

22. Morcet JF, Safar M, Thomas F, Guize L, Benetos A. Associations between heart rate and other risk factors in a large French population. J Hypertens. 1999;17(12 Pt 1):1671-6.

23. Palatini P. Role of elevated heart rate in the development of cardiovascular disease in hypertension. Hypertension. 2011;58(5):745-50.

24. Landsberg L, Aronne LJ, Beilin LJ, Burke V, Igel LI, Lloyd-Jones D, et al. Obesity-related hypertension: pathogenesis, cardiovascular risk, and treatment-a position paper of the The Obesity Society and The American Society of Hypertension. Obesity (Silver Spring). 2013;21(1):8-24. 